\title{
Sirtuin1, Inducible Nitric Oxide Synthase in Newly Diagnosed Iraqi Diabetic Patients
}

\author{
Mahmood Abdulhameed Hazim, Perry H. Saifullah ${ }^{1}$ and Beydaa Ahmed Abd ${ }^{2}$ \\ ${ }^{1}$ Department of Biochemistry, College of Science, University of Baghdad, Baghdad-Iraq. \\ ${ }^{2}$ Department of Biochemistry, University of Al Mustansiriya, Baghdad-Iraq.
}

\section{Abstract}

In Mammals Sirtuins (SIRTs) are members of the silent information regulator two family Sirtuin 1 regulate a variety of cellular functions. It shows anti-oxidative, anti-inflammatory, and anti-apoptotic effects against cellular damage.SIRT1 conserves the cells by the mitochondrial biogenesis organizing, cellular energy and oxido reduction state. Vascular tissues are protected by SIRT1 too. In diabetic patients mutation in exon1 of SIRT1 (L107P) in insulin-generating cells conducted in over production of nitric oxide synthase (iNOS), TNF- $\alpha$.

Assessment of SIRT1 protein levels in newly diagnosed Iraqi diabetic in regards to family history Age, gender, and duration of disease, and its correlation with biochemical parameter in the same group. Measurement of iNOS, TNF- $\alpha$.

This study involved totally 40 volunteers. This group were subdivided (20) volunteers as newly diagnosis (DMT1) duration disease $<1$ year, group1 was subdivided to 10 male and 10 female: (10 with family history and 10 without family history) and group two healthy volunteers. Group 1 All DMT1 were under insulin treatment. Healthy Volunteers (20) included in this study as control groups. None Healthy Volunteers were alcoholic, smoke, or having a history of (CVD) cardiovascular disease, thyroid disease, and hormonal abnormalities problems were exempted from this study.

In the present study SIRT1, TNF-alpha, iNOS were measured by enzyme linked immune absorbent assay (ELISA). Biochemical parameters fasting glucose, body mass index (BMI), urea, creatinine and lipid profile that were measured by spectrophotometer technique in patients and healthy volunteers groups.

The Statistical Analysis System- SAS (2012) program was used to effect of difference factors in study parameters. Least significant difference -LSD test (ANOVA) was used to significant compare between means. Estimate of correlation coefficient between difference parameters in this study.

The results showed that a highly significant increase in levels of FBG, Urea, creatinine and lipid profile except HDL was decrease levels, BMI was decrease in newly diagnosis DMT1 with healthy volunteers groups. A significant decrease in SIRT1 protein, and a highly significant increase in TNF-alpha and iNOS in newly diagnosis DMT1 with healthy volunteers groups. A highly negative significantly correlation coefficient between SIRT1 and F.G., TG., VLDL,TG/HDL, A.I. and negative significantly correlation duration, urea, creatinine,T.CH., LDL. And non-significant correlation with age, BMI, HDL, CH/HDL and LDL/HDL.. Effect of gender were insignificant of SIRT1. Effect of family history in patients. SIRT1 were all insignificant in patients with family history as with non-family history group. SIRT1 could decreases in the sera of DMT1 patients with family history, the decreased SIRT1 level reflect a mutation in SIRT1 gene, the decreases in SIRT1 on increases the incident of DMT1 complication. [DOI: 10.22401/JUNS.21.1.01]

Keywords: SIRT1, DMT1, iNOS, alfa-TN, lipid profile, body mass index.

\section{Introduction}

Sirtuin as a term came from The silent information regulator 2 gene (Sir2), was initially found in Saccharomyces cerevisiae and was called (Sir2) after its action to attenuate silencing gene. Once found, sirtuins were quickly distinguishes in yeast, mammals, plants, and bacteria ${ }^{[1]}$. Sir2 or Siruin (SIRT) proteins are a type of proteins having either deacylase or mono-ADP-ribosyltransferase, function, involving demalonylase, depalmitoylase, demyristoylase, desuccinylase and deacetylase action $^{[2]}$. Sirtuins can be found and initiated in kidney, liver, spleen, lung, heart, muscle, brain, testis, ovary, thymus, pancreas, white and chestnut fat tissue. The confinement of 
Sirtuins (SIRT) proteins contrast and matter in the cell, consequently, the diverse limitations create different physiologic and conceivably pathologic metabolic impacts under certain stress conditions. There are seven types of Sirtuins (SIRT), SIRT1 dwells both in the mitochondria and cytoplasm and SIRT2 is principally found in the cytoplasm, be that as it may, it can be moved into the mitochondria in a cell cycle-subordinate way. SIRT3, - 4 and-5 found in the mitochondrion. The last two individuals from the SIRT protein family, SIRT6 and -7 are found in the core and the nucleolus of the cell, respectively. The SIRT1 human quality is situated at chromosome (Chr 10q21.3.), where it was demonstrated that deacetylation inhibits transcriptional initiation $^{[3]}$.

SIRT 1 mutation was identified as (SNP) at $\mathrm{T} \rightarrow \mathrm{C}$ in exon1. Leading a leucine to proline at 107 site mutation in the SIRT1 protein. This SNP on chromosome 10 is related to insulin activity, inhibiting signaling and leading to damage beta cell ${ }^{[4]}$.

Tumor necrosis factor alpha also called $\mathrm{TNF} \alpha$, cachectin, or cachexin, and required in inflammation systemic, is one of the cytokines that make up the intense stage reaction. It is product mostly by initiated macrophages, $\mathrm{TNF} \alpha$ can be delivered by numerous other cell sorts, for example, CD4+ lymphocytes, neutrophils, neurons, eosinophils, and mast cells. It is included in beta-cell harm prompting DMT1, causes insulin resistance connected with weight and is of impact in the arrangement of atherosclerotic vascular injuries. There is relationship of this cytokine with metabolic control and cardiovascular danger variables in patients with DMT $1^{[5]}$.

Nitric oxide (NO), which is a free radical with certain natural consequences for cells, is a gaseous flagging molecule that is required for pancreatic physiology, however can likewise assume a role in pathophysiological processes of the pancreas and include in $\beta$ eta cell ${ }^{[6]}$.

\section{Methods}

\section{Sampling Collection}

Five mls of blood were gotten by venipuncture from all volunteers, the blood was placed in a separator gel tube and let for 2 hours at room temperature to got clot. Tubes were centrifuged at $(1000 \mathrm{x}$ g) for 15 minutes. Serum was obtained, divided into several eppendorf tube and kept under $\left(-20^{\circ} \mathrm{C}\right)$ until test.

\section{Estimate of BMI}

Body Mass Index (BMI) Formula and Table Body Mass Index (BMI) is a number calculated from a person's weight and height. BMI is a screening method that may indicate underlying health issues ${ }^{[7]}$.

\section{Result and Discussion}

Table (1)

Correlation coefficient between SIRT1, TNF- $\alpha$, iNOS with other para meters is that for all groups.

\begin{tabular}{|c|c|c|c|c|}
\hline Test & $\begin{array}{c}\text { Patients newly } \\
\text { diagnosis } \\
\text { Mean } \pm \text { SE }\end{array}$ & $\begin{array}{c}\text { Healthy } \\
\text { volanteers } \\
\text { Mean } \pm \text { SE }\end{array}$ & $\mid$\begin{tabular}{|l|} 
P-vahe \\
\end{tabular} & LSD value \\
\hline Age (year) & $\begin{array}{c}15.15 \pm 1.66 \mathrm{~b} \\
7.00-31.00\end{array}$ & $\begin{array}{c}31.65 \pm 1.81 \mathrm{a} \\
19.00-52.00\end{array}$ & 0.0001 & $5.482^{* *}$ \\
\hline BMI $\left(\mathrm{kg} / \mathrm{m}^{2}\right)$ & $\begin{array}{c}19.60 \pm 0.60 \mathrm{~b} \\
14.60-26.00\end{array}$ & $\begin{array}{c}27.19 \pm 0.82 \mathrm{a} \\
21.20-35.50\end{array}$ & 0.0001 & $2.575^{* *}$ \\
\hline Duration (year) & $\begin{array}{c}0.657 \pm 0.09 \mathrm{c} \\
0.02-1.50\end{array}$ & (--. & 0.0001 & $3.132^{* *}$ \\
\hline F.G.(mg/dL) & $250.20 \pm 23.33 \mathrm{a}$ & $96.50 \pm 1.65 \mathrm{~b}$ & 0.0001 & $62.317^{* *}$ \\
\hline Tri(mg/dL) & $125.05 \pm 8.90 \mathrm{~b}$ & $88.35 \pm 2.97 \mathrm{~b}$ & 0.0001 & $41.62^{* *}$ \\
\hline T.CH. (mg/dL) & $171.00 \pm 4.42 \mathrm{~b}$ & $158.10 \pm 5.11 \mathrm{~b}$ & 0.0001 & $32.617^{* *}$ \\
\hline EIDL(mg/dL) & $41.95 \pm 1.45 \mathrm{~b}$ & $58.25 \pm 1.31 \mathrm{a}$ & 0.0001 & $5.168^{24 \pi}$ \\
\hline LDL(mg/dL) & $104.15 \pm 2.49 \mathrm{bc}$ & $82.30 \pm 4.69 \mathrm{c}$ & 0.0001 & $28.02^{7+4}$ \\
\hline VLDL(mg/dL) & $24.90 \pm 1.74 \mathrm{~b}$ & $17.55 \pm 0.59 \mathrm{c}$ & 0.0001 & $5.982^{444}$ \\
\hline LDL/HDL & $2.55 \pm 0.07 \mathrm{~b}$ & $1.41 \pm 0.09 \mathrm{c}$ & 0.0001 & $0.745^{\text {का4 }}$ \\
\hline Tri/HDL & $2.98 \pm 0.20 \mathrm{~b}$ & $1.51 \pm 0.05 \mathrm{~b}$ & 0.0001 & $1.147^{34}$ \\
\hline CH/HDL & $4.19 \pm 0.11 \mathrm{~b}$ & $3.37 \pm 0.67 \mathrm{~b}$ & 0.0001 & $1.274^{24}$ \\
\hline A.LP. & $0.451 \pm 0.03 \mathrm{~b}$ & $0.171 \pm 0.02 \mathrm{c}$ & 0.0001 & $0.102^{2 \sqrt{4 x}}$ \\
\hline Urea(mg/dL) & $33.05 \pm 071 \mathrm{~b}$ & $25.76 \pm 1.21 \mathrm{c}$ & 0.0001 & $4.558^{74}$ \\
\hline Creatinine(mg/dL) & $0.827 \pm 0.02 \mathrm{~b}$ & $0.621 \pm 0.01 \mathrm{c}$ & 0.0001 & $0.161^{\text {th }}$ \\
\hline SIRTI (ng/mL) & $0.795 \pm 0.19 \mathrm{ab}$ & $0.898 \pm 0.02 \mathrm{a}$ & 0.0510 & $0.420^{*}$ \\
\hline TNF- $x(p g / m L)$ & $60.52 \pm 11.02 \mathrm{a}$ & $16.69 \pm 3.36 \mathrm{c}$ & 0.0039 & $23.524^{274}$ \\
\hline iNOS (ng/L) & $8.15 \pm 1.14 \mathrm{~b}$ & $6.21 \pm 1.15 \mathrm{~b}$ & 0.0084 & $3.634^{74}$ \\
\hline \multicolumn{5}{|c|}{${ }^{*}(\mathrm{P}<0.05),{ }^{* *}(\mathrm{P}<0.01)$} \\
\hline
\end{tabular}

Body Mass Index (BMI) Was measured for all subject in this study BMI was found to be high significantly This results is agreement with, high glucose in DMT1, an impression of lacking insulin, brings about eye ailment, kidney sickness, nerve harm, and an expanded danger of cardiovascular illness that may show up 10-15 years after diagnosis and loss weight. Fasting Blood Glucose (FBG) showed a high significant which is in agreement with the study of Mahato et al., 2011 ${ }^{[8]}$. The relationship between glucose and insulin in the 
basal state reflects the balance between hepatic glucose output and insulin secretion, which is maintained by a feedback loop between the liver and B-cells. Triglyceride level was found to be high significantly Patients with diabetes or hypertension have a tendency to be dyslipidemic with high plasma Triglyceride which are perceived as danger variables for cardiovascular ailment. Total serum cholesterol levels that were high significantly The results is in agreement with optioned in diabetic human by Salah Attalah (2007). Who observed an increase of serum cholesterol level in diabetic patients may be due to increased synthesis of cholesterol ${ }^{[9]}$. HDL level founded a highly significant furthermore, HDL assumes a noteworthy part in digestion system of triglyceride-rich lipoproteins, HDL serves as a powerful endogenous inhibitor of inflammation and LDL oxidation. ${ }^{[10]}$ LDL level were highly significant The causes of increase LDL-cholesterol in DMT1 patient could be due to insulin resistant and metabolic syndrome, poor thyroid function and infection $^{[11]}$. VLDL were a highly significant in DMT1 the major variation from the norm of plasma lipoprotein is excessed the level of VLDL. In noteworthy increment in VLDL-C in DMT1 patients may be because of impeded lipoprotein lipase_mediated VLDL removal from plasma duration DMT1. Serum of LDL/HDL ratio were a highly significant Serum LDL-C/HDL proportion was observed to be increased in DM patients. Many clinical studies have found the LDL-C/HDLproportion to be a good indicator of CVD danger. Serum TG/HDL were highly significantly Serum of Atherogenic Index TG/HDL demonstrate an expansion in DMT1 patient. The hypertriglyceridemia, low HDL-C level, and high TG/HDL proportion connected with insulin resistance since insulin influences TG and HDL digestion system ${ }^{[12]}$. Serum CH. /HDL were highly significantly $\mathrm{CH}$./HDL proportion is viewed as a more specific and sensitive risk of cardiovascular disease than cholesterol ${ }^{[13]}$. Atherogenic Index of Plasmawere highly significantly this study agreement with Tariq M. (2012) demonstrated increased A.I.P. in DMT1 Patents, and more elevated in DMT1 with complication CVD ${ }^{[14]}$. Serum of Urea level were a highly significant
This results was in concurrence with Salim Jasim (2010) expressed the relationship of raised blood urea with development renal capacity through DMT1 its part in early renal capacity decline in DMT1 before protein urea develops ${ }^{[15]}$. Serum of Creatinine level were a highly significant this results in agreement with Kamal Adel Amin. and et al (2011) increased creatinine level in DMT1, the focal pathophysiologic denominator for every risk CVD of DMT1 including nephropathy. Variations from the norm of NO creation modulate renal structure and capacity in DMT1 ${ }^{[16]}$.

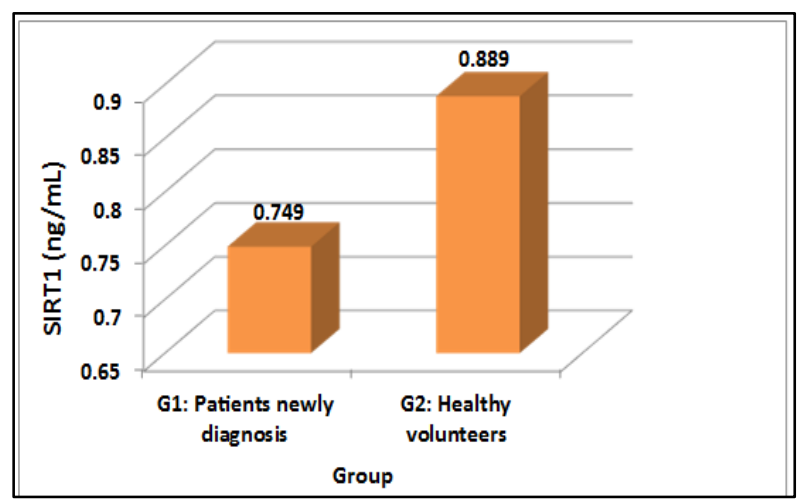

Fig.(1): Compare between difference group in SIRT1.

SIRT1 level showed a significant difference value of $(\mathrm{LSD}=0.420)$. And $\mathrm{P}$-value $(\mathrm{P}=0.051)$. SIRT1 level $(0.795 \pm$ $0.19 \mathrm{ng} / \mathrm{mL})$ as compared to healthy volunteers $(0.898 \pm 0.02 \mathrm{ng} / \mathrm{mL})$ as shown in Table (1) \& Fig.(1). The results is in agreement with Rabi (2014), who showed that the hepatic production of glucose in decreased by SIRT1 through deacylation and energizing of the AMPAK Kinase LKB1, and thus studying down glucose. TG, $\mathrm{CH}$. hepatic output, and boost fatty acid oxidation. SIRT1 is activated by AMPK through substrate (NAD-) increasing. Hyperglycemia disrupt this interaction between SIRT1 and AMPK, resulting in decreasing SIRT1 expansion ${ }^{[17]}$.

Cytokines assume a part in the autoimmune system process prompting pancreatic damage ${ }^{[18]}$. 


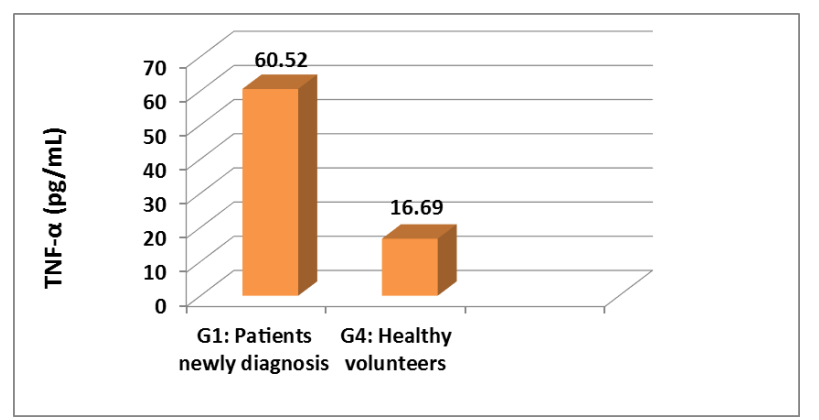

Fig.(2): Comparison between difference groups in TNF- $\alpha$.

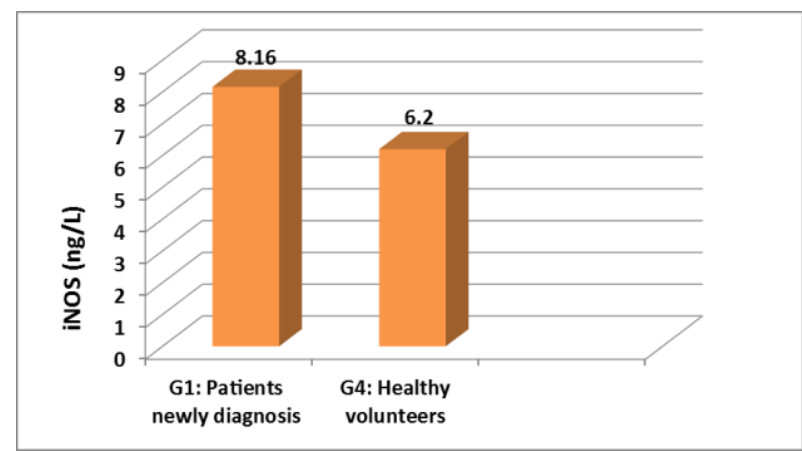

Fig.(3): Comparison between difference groups in iNOS.

Tumor Necrosis Factor alpha level showed a highly significant value of $(\mathrm{LSD}=23.524)$ and $\mathrm{P}$-value $(\mathrm{P}=0.0039)$ difference in DMT1 patients newly diagnosis, when compared to Healthy volunteers with a mean value of $(16.69 \pm 3.36 \mathrm{pg} / \mathrm{mL})$ as shown in Table (1) \& Fig.(2). This results in agreement with several studies that demonstrated serum levels of TNF- $\alpha$ are increased in patients with newly diagnosed DMT1 compared with those in Healthy volunteers, TNF- $\alpha$ and different cytokines assume a part in the autoimmune system process prompting pancreatic damage $^{[18]}$.

Inducible Nitric oxide synthase results showed a highly significant value of (LSD $=$ 3.634) and $\mathrm{P}$-value $(\mathrm{P}=0.0084)$ difference in newly diagnosis DMT1 patients, when compared to Healthy volunteers with a mean value of $(6.21 \pm 1.15 \mathrm{ng} / \mathrm{L})$ as shown in Table(1) \& Fig.(3) this results in agreement with other study that shown, Nitric oxide (NO) and its isoforms, inducible, neuronal, endothelial is importance flagging molecule that demonstrations in numerous tissues to control a differing range of physiological and cell forms. In view of its significance in vascular capacity, abnormal generation of NO, as happens in various ailment states, for example, DM and failure heart, can adversely influence blood stream and other vascular capacities $^{[19]}$.

Correlation coefficient between SIRT1 with other parameters:

Table (2)

Correlation coefficient between SIRT1 with other para meters is that for all groups.

\begin{tabular}{||c||c||}
\hline \multirow{2}{*}{$\begin{array}{c}\text { Parameters } \\
\text { correlated }\end{array}$} & $\begin{array}{c}\text { Correlation } \\
\text { coefficient (r) }\end{array}$ \\
\cline { 2 - 3 } & SIRT1 \\
\hline \hline Age & $-0.11 \mathrm{NS}$ \\
\hline \hline BMI & $-0.13 \mathrm{NS}$ \\
\hline \hline Duration & $-0.25 *$ \\
\hline F.G. & $-0.32 * *$ \\
\hline Urea & $-0.24 *$ \\
\hline Creatinine & $-0.24 *$ \\
\hline TriG. & $-0.30 * *$ \\
\hline T. Chol. & $-0.25 *$ \\
\hline \hline HDL & $0.06 \mathrm{NS}$ \\
\hline LDL & $-0.24 *$ \\
\hline \hline VLDL & $-0.30 * *$ \\
\hline \hline Chol/HDL & $-0.13 \mathrm{NS}$ \\
\hline \hline LDL/HDL & $-0.17 \mathrm{NS}$ \\
\hline Tri/HDL & $-0.27 * *$ \\
\hline A.I & $-0.31 * *$ \\
\hline (P<0.05), $* *(\mathrm{P}<0.01)$, NS: Non-significant. \\
\hline \hline
\end{tabular}

Table (2) demonstrated, There are inversely relation between SIRT1 vs. age and BMI in this study but no significant P-value $>0.05$ $(\mathrm{r}=-0.11,-0.13)$ respectively. And inversely relation between SIRT1and duration disease of DMT1 shown significant difference ( $\mathrm{P}$-value $<0.05, \mathrm{r}=-0.25$ ).

Relation between SIRT1 and fasting glucose was inversely and shown a highly significant difference (P-value $<0.01, \mathrm{r}=-0.32$ ). Because SIRT1 regulate function of the pancreas and over expression of SIRT1 showed a positive controlling of insulin (Moynihan et al., 2005) SIRT1 is through to advance insulin emission by repressing the transcription of UCP(uncoupling protein)gene, prompting an expansion in ATP/ADP proportion a known trigger of insulin emission $^{[20]}$.

Relation between SIRT1 vs. Urea and creatinine was inversely and shown a significant difference ( $\mathrm{P}$-value $<0.05, \mathrm{r}=-0.24)$. In kidney, showed that Sirt1 is abundantly 
expressed in the interstitial cells of renal inward medulla, where it assumes an important role against increasing oxidative anxiety. This result is predictable with the perception that there are abnormal amounts of oxidative anxiety markers under physiological conditions in the renal internal medullary interstitium. Various remarkable components of renal medullary interstitium are known to contribute to increasing oxidative anxiety, involving low blood stream and oxygen and additionally high osmotic anxiety causes of high level of urea ${ }^{[21]}$.

Relation between SIRT1 and Triglyceride was inversely and shown a highly significant difference (P-value $<0.01, \mathrm{r}=-0.30$ ). SIRT1 regulates hepatic triglyceride synthesis by activation gene for example the sterol regulatory element binding protein SREBP1. Therefore decrease in SIRT1 level effected to accumulation triglyceride and degreased HDL (Li et al., 2007) $^{[22]}$.

Relation between SIRT1 and Total Cholesterol was inversely and shown a significant difference $(\mathrm{P}$-value $<0.01, \mathrm{r}=-0.30)$. SIRT1 additionally manages hepatic cholesterol and bile acid homeostasis through direct modulation of the liver $X$ receptors (LXRs) and farnesoid X receptor (FXR), LXR and FXR are nuclear receptors that capacity as vital cholesterol sensors. It has been previously demonstrated that SIRT1 can specifically deacetylate LXRs, bringing about excessed LXR turnover and enhanced target gene expression $^{[23]}$.

Relation between SIRT1 and HDL was non-significant difference (P-value $>0.05$, $r=0.06)$. Systemic deletion of SIRT1 in mice brings about diminished serum HDL levels ${ }^{[23]}$.

Relation between SIRT1 and LDL was inversely and shown a significant difference (P-value $<0.01, \mathrm{r}=-0.24)$. Relation between SIRT1 and VLDL was inversely and shown a highly significant difference (P-value $<0.01$, $\mathrm{r}=-0.30)$. SIRT1 gene is associated with serum LDL-C and HDL-C levels, with decreased LDL-cholesterol and increased HDLcholesterol levels ${ }^{[24]}$.

Relation between SIRT1 vs. Chol/HDL and LDL/HDL was inversely and shown nonsignificant difference ( $\mathrm{P}$-value $>0.05, \mathrm{r}=-0.13$, $\mathrm{r}=-0.27)$ respectively. Relation between SIRT1 vs. Tri/HDL and A.I. was inversely and shown a highly significant difference (P-value $<0.01, \mathrm{r}=-0.27, \mathrm{r}=-0.31$ ) respectively. In atherogenesis, ceaseless endothelial brokenness is a trigger of plaque formation, and endothelial SIRT1 overexpression has been appeared to protect atherosclerosis by enhancing vascular function. Nevertheless, the significance of SIRT1 on the cell and molecular events representing atherogenesis is obscure. As numerous objectives of SIRT1 may assume a part in plaque arrangement, it is likely that eNOS is not the only mechanism by which SIRT1 anticipates atherogenesis. Specifically, the part of SIRT1 in monocyte adhesion, lipid uptake, and foam cell arrangement stays to be determined ${ }^{[24]}$.

Effect of gender in SIRT1 study in patients:

Table (3)

Effect of gender in SIRT1 in patients.

\begin{tabular}{|c|c|c|c||}
\hline \multirow{2}{*}{$\begin{array}{c}\text { Parameters } \\
\text { correlated }\end{array}$} & \multicolumn{2}{|c|}{ Gender } & \multirow{2}{*}{$\begin{array}{c}\text { LSD } \\
\text { value }\end{array}$} \\
\cline { 2 - 3 } & Male & Female & \\
\hline \hline SIRT1 & 0.703 & 0.486 & 0.457 \\
$(\mathrm{ng} / \mathrm{mL})$ & \pm 0.17 & \pm 0.09 & NS \\
\hline \multicolumn{2}{|c|}{$*(\mathrm{P}<0.05)$, NS: Non-significant. } \\
\hline
\end{tabular}

The results as shown in Table (3) revealed that there were a non-significant effect of gender of SIRT1 protein levels, with higher mean value of SIRT1 in male as compared to female in studied groups. This result observed an increment in SIRT1 protein level in female mice under hyperoxia-exposed associated with reduce PPAR- $\gamma$ levels and greater SOD2 and eNOS activity. On the other hand greater PPAR $-\gamma$ and reduced SOD2 activity were correlated with unaltered SIRT1 expression. Their results showed that female are had exceeded resistance to hyperoxia and more efficacious defense system, this could be to the advantageous influence of $\mathrm{LH}$ and $\mathrm{FSH}$ hormones $^{[25]}$. 
Family history influence on the SIRT1 in patient's :

Table (4)

Effect of family history in SIRT1 in patients.

\begin{tabular}{||c||c||c||c|}
\hline \multirow{2}{*}{$\begin{array}{c}\text { Parameters } \\
\text { correlated }\end{array}$} & $\begin{array}{c}\text { Family history } \\
\text { (DMT1+DMT2) }\end{array}$ & $\begin{array}{c}\text { Non } \\
\text { Family } \\
\text { history }\end{array}$ & $\begin{array}{c}\text { LSD } \\
\text { value }\end{array}$ \\
\hline \hline $\begin{array}{c}\text { SIRT1 } \\
(\mathrm{ng} / \mathrm{mL})\end{array}$ & $0.556 \pm 0.11$ & $\begin{array}{c}0.797 \pm \\
0.10\end{array}$ & $\begin{array}{c}0.295 \\
\text { NS }\end{array}$ \\
\hline \hline$*(\mathrm{P}<0.05), * *(\mathrm{P}<0.01), \mathrm{NS}:$ Non-significant. \\
\hline
\end{tabular}

Influence of family history of diabetes mellitus of the SIRT1 was examined in this study. First all patients that were included in this study were DM1 while their parents or first degree relatives might have had type1 or 2 DM as shown in Table (4). SIRT1 were all highly insignificant in patients with family history as with non-family history group.

\section{Conclusion}

SIRT1 could decreases in the sera of DMT1 patients with family history, the decreased SIRT1 level reflect a mutation in SIRT1 gene, the decreases in SIRT1 on increases the incident of DMT1 complication.

\section{References}

[1] Marks, P., Rifkind, R.A., Richon, V.M., Breslow, R. et al.، "Histone deacetylases and cancer: Causes and therapies", Nat. Rev. Cancer, 1, 194-202, 2001.

[2] North BJ, Verdin E, "Sirtuins: Sir2-related NAD-dependent protein deacetylases", Genome Biol., 5 (5), 224, 2004.

[3] Michishita E, Park JY, Burneskis JM, Barrett JC, Horikawa I., "Evolutionarily conserved and nonconserved cellular localizations and functions of human SIRT proteins.”, Mol Biol Cell., 16, 4623-4635, 2005.

[4] Price NL, Gomes AP, Ling AJ, Duarte FV, Martin-Montalvo A, North BJ, et al., "SIRT1 is required for AMPK activation and the beneficial effects of resveratrol on mitochondrial function." ,Cell Metab 15(5), 675-90, 2012.

[5] Yadav J., Sagami I., Shimizu T., J. Inorg. Biochem, 95, 25-30, 2003.

[6] Keklikoglu N. "Inducible nitric oxide synthase immunoreactivity in healthy rat pancreas", Folia Histochem Cytobiol, 46, 213, 2008.
[7] Fareed M, Afzal M., "Evidence of inbreeding depression on height, weight, and body mass index: A population-based child cohort study", Am J Hum Biol., 26,784-795, 2014.

[8] Ram Vinod Mahato, Prajwal Gyawali, Pramod Psd. Raut.(2011) "Association between glycaemic control and serum lipid profile in type 2 diabetic patients: Glycated hemoglobin as a dual biomarker", J. Biomedical Research, 22,3, 2011.

[9] Salah, Attalah., "Markers for side complications a moung diabetic mellitus patients", ph. D. thesis, Department of Natural Science and life, Algeria university, 2007.

[10] Navab M, Berliner JA, Subbanagounder G, Hama S, "HDL and the inflammatory response induced by LDL-derived oxidized phospholipids.", Arterioscler Thromb Vasc Biol, 21, 481-488, 2001.

[11] Denise Prado Momesso, Isabela BussadeI, Giovanna A. Balarini Lima. Leniane Pereira Coelho Fonseca, Luis Augusto Tavares Russo, Rosane Kupfer, "Body composition, metabolic syndrome and insulin resistance in type 1 diabetes mellitus", Arq Bras Endocrinol Metab, 55 (3), 2011.

[12] Miller M, Cannon CP, Murphy SA, Qin J, Ray KK, Braunwald E, "Investigators Impact of triglyceride levels beyond lowdensity lipoprotein cholesterol after acute coronary syndrome in the Prove it-Timi 22 trial”, J Am Coll Cardiol., 51 (7), 724-730, 2008.

[13] Genest J, Frohlich J, Fodor G, McPherson R. "the Working Group on Hypercholesterolemia and Other Dyslipidemias. Recommendations for the management of dyslipidemia and the prevention of cardiovascular disease", CMAJ., 169 (921-924), 2003.

[14] Tariq M, Ali Rajab., "Comparative study for Atherogenic Index of Plasma (AIP) in patient with type1 Diabetes Mellitus, type2 Diabetes Mellitus, Betathalassemia and Hypothyroidism", Int J Chem Res., 2(1-9), 2012.

[15] Salim, Jasim, Khalaf, Tikrit Medical Journal, 16(2), 84-87, 2010.

[16] Kamal Adel Amin, Ezzat Mohamed Awad and Mohammed Ahmad Nagy., "Effects of panax quinquefolium on streptozotocin-induced diabetic rats: role of 
C-peptide, nitric oxide and oxidative stress", Int J Clin Exp Med, 4(2),136-147, 2011.

[17] Rabi Yacoub, Kyung Lee, and John Cijiang He., "The Role of SIRT1 in Diabetic Kidney Disease", Front Endocrinol (Lausanne), 5, 166, 2014.

[18] Argiles JM, Lopez-Soriano J, LopezSoriano FJ, "Cytokines and diabetes: the final step? Involvement of TNF- $\alpha$ in both type I and II diabetes mellitus.", Horm Metab Res, 26, 447- 449, 1994.

[19] Habib S, Ali A. Biochemistry of nitric oxide. Indian J Clin Biochem., 26 (1), 3-17, 2011.

[20] Moynihan KA, Grimm AA, Plueger MM, Bernal-Mizrachi E, Ford E, Cras-Méneur C, Permutt MA, Imai S., "Increased dosage of mammalian Sir2 in pancreatic beta cells enhances glucose-stimulated insulin secretion in mice.", Cell Metab., (2), 10517, 2006.

[21] Neuhofer W, Beck FX. "Survival in hostile environments strategies of renal medullary cells.", Physiology (Bethesda)., 21(1-4), 171-180, 2006.

[22] Li X, Zhang S, Blander G, Tse JG, Krieger M, Guarente L, "SIRT1 deacetylates and positively regulates the nuclear receptor LXR.”, Mol Cell., 28(1), 91-106, 2007.

[23] Kemper JK, Xiao Z, Ponugoti B, Miao J, Fang S, Kanamaluru D, Tsang $S$, et al. "FXR acetylation is normally dynamically regulated by p300 and SIRT1 but constitutively elevated in metabolic disease states." Cell Metab, 10, 392-404, 2009.

[24] Tomoko Inamori, Toshinao Goda, Nobuhiko Kasezawa and Kimiko Yamakawa-Kobayashi, "The combined effects of genetic variation in the SIRT1 gene and dietary intake of n-3 and n-6 polyunsaturated fatty acids on serum LDL$\mathrm{C}$ and HDL-C levels: a population based study" Lipids in Health and Disease, 12(4), 2013.

[25] Bini EI, Mata Espinosa D, Marquina Castillo B, Barrios Payán J, Colucci D, Cruz AF, et al., "The Influence of Sex Steroid Hormones in the Immunopathology of Experimental Pulmonary Tuberculosis.", PLoS ONE 9(4), e93831, 2014. 